\title{
Microwave spectrum, structure, barrier to internal rotation, dipole moment, and deuterium quadupole coupling constants of the ethylene-sulfur dioxide complex
}

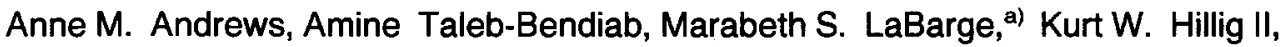 \\ and Robert L. Kuczkowski \\ Department of Chemistry, The University of Michigan, Ann Arbor, Michigan 48109-1055
}

(Received 5 April 1990; accepted 31 July 1990)

\begin{abstract}
The microwave spectra of the complex between ethylene and sulfur dioxide and nine of its isotopic species have been observed in a Fourier transform microwave spectrometer. The spectra exhibit $a$ and $c$ dipole selection rules; transitions of the normal species and several of the isotopically substituted species occur as tunneling doublets. The complex has a stacked structure with $C_{s}$ symmetry; the $\mathrm{C}_{2} \mathrm{H}_{4}$ and $\mathrm{SO}_{2}$ moieties both straddle the mirror plane with the $\mathrm{C}_{2}$ axis of $\mathrm{SO}_{2}$ crossed at $90^{\circ}$ to the carbon-carbon bond axis (i.e., only the $\mathrm{S}$ atom lies in the symmetry plane). The distance between the centers of mass $\left(R_{\mathrm{cm}}\right)$ of $\mathrm{C}_{2} \mathrm{H}_{4}$ and $\mathrm{SO}_{2}$ is 3.504 (1) $\AA$ and the deviation of their planes from perpendicular to $R_{\mathrm{cm}}$ is $21(2)^{\circ}$ and $12(2)^{\circ}$, respectively. The tunneling splittings arise from a rotation of the ethylene subunit in its molecular plane. The barrier to internal rotation is $30(2) \mathrm{cm}^{-1}$. The dipole moment of the complex is 1.650 (3) D. The deuterium nuclear quadrupole coupling constants for $\mathrm{C}_{2} \mathrm{H}_{3} \mathrm{D} \cdot \mathrm{SO}_{2}$ are $\chi_{a a}=-0.119(1) \mathrm{MHz}, \chi_{b b}=0.010(1) \mathrm{MHz}$, and $\chi_{c c}=0.109$ (1) $\mathrm{MHz}$. The binding energy is estimated to be $490 \mathrm{~cm}^{-1}$ from the pseudo-diatomic approximation. A distributed multipole electrostatic model is explored to rationalize the structure and binding energies.
\end{abstract}

\section{INTRODUCTION}

The tendency of sulfur dioxide to form weak complexes with alkene ${ }^{1}$ and aromatic ${ }^{2}$ compounds has been known for some time. It was inferred from such studies that the $\pi$ system of the hydrocarbon interacts with the $\mathrm{SO}_{2}$, although detailed structural data was usually lacking. The only previous spectroscopic studies of the complex between ethylene and sulfur dioxide $\left(\mathrm{C}_{2} \mathrm{H}_{4} \cdot \mathrm{SO}_{2}\right)$ are matrix IR investigations $^{3}$ which indicate that small changes $\left(1-5 \mathrm{~cm}^{-1}\right)$ occur in the $\mathrm{SO}_{2}$ vibrations upon complexation. Evidence for the gas phase complex was obtained by Muenter and co-workers in a molecular beam mass spectrometry experiment. ${ }^{4}$ From studies of the competitive formation of $\mathrm{C}_{2} \mathrm{H}_{4} \cdot \mathrm{SO}_{2},\left(\mathrm{SO}_{2}\right)_{2}$, and $\left(\mathrm{C}_{2} \mathrm{H}_{4}\right)_{2}$, they reported a favorable interaction between $\mathrm{C}_{2} \mathrm{H}_{4}$ and $\mathrm{SO}_{2}$. Recently, we reported the observation of the microwave spectrum of the complex in a Fourier transform microwave (FTMW) spectrometer. ${ }^{5}$ From the spectrum, which exhibited tunneling doublets of undetermined origin, we deduced the gross geometry of the complex as having the two molecular planes stacked one above the other. A recent study of a similar complex between ethylene and ozone also identified a stacked, near parallel planes structure. ${ }^{6}$

Here we present a much more detailed study of the $\mathrm{C}_{2} \mathrm{H}_{4} \cdot \mathrm{SO}_{2}$ system. In addition to further analyzing the spectrum of the normal species, we have assigned the spectra of several isotopically substituted species, determined the dipole moment, and assigned the deuterium nuclear quadrupole coupling hyperfine structure in the singly deuterated isotope. From these measurements, we have been able to determine more accurately the structure of the complex and the nature of the internal motion.

\footnotetext{
a) Current Address: Dow Chemical Co., Midland, MI 48667.
}

There has been considerable discussion in the literature on the interpretation of the structures of weakly bound complexes. It has been observed in many weak complexes, ${ }^{7,8}$ and particularly in hydrogen bonded complexes, ${ }^{9}$ that the orientational preference of the subunits is determined largely by electrostatic interactions. We have used the distributed multipole model as proposed by Buckingham and Fowler ${ }^{7}$ to model these interactions in $\mathrm{C}_{2} \mathrm{H}_{4} \cdot \mathrm{SO}_{2}$. This simple approach appears to be useful for interpreting the structure of the $\mathrm{C}_{2} \mathrm{H}_{4} \cdot \mathrm{SO}_{2}$ complex.

\section{EXPERIMENTAL}

\section{A. Instrumental}

The rotational spectrum of the complex was measured in the region between 6.6 and $18 \mathrm{GHz}$ with a Fourier transform microwave spectrometer of the Balle-Flygare type ${ }^{10}$ using a modified Bosch fuel injector as a pulsed nozzle source. ${ }^{11}$ Experimental line widths were 20 to $30 \mathrm{kHz}$ and center frequencies were estimated to be accurate to $\pm 2-3$ $\mathrm{kHz}$ for transitions unsplit by deuterium nuclear quadrupole coupling. For many of the deuterated species, the lines were broadened up to $100 \mathrm{kHz}$ by unresolved quadrupole splittings; center frequencies were taken as the position of maximum intensity of the broadened lines and are estimated to be accurate to $\pm 20-30 \mathrm{kHz}$.

The spectrometer is equipped with steel mesh plates to allow for the measurement of Stark effects; the details are described elsewhere. ${ }^{12}$ The electric field was calibrated with the $J=1-0, M_{J}=0$ transition of $\mathrm{OCS}^{13}$ on each day that Stark effects were measured. Stark shifts were typically measured at six to ten different field strengths. 


\section{B. Samples}

The spectra were observed with a gas mixture of approximately $1 \%$ ethylene, $1 \% \mathrm{SO}_{2}$, and $98 \%$ rare gas at a total backing pressure of 1 to $2 \mathrm{~atm}$. In most cases the carrier gas was neon, as this gave the strongest signals. Much of the early searching was done using argon as the carrier gas and one of the isotopically substituted species was observed in helium.

With the exception of $\mathrm{C}_{2} \mathrm{H}_{4} \cdot{ }^{34} \mathrm{SO}_{2}$, which was observed in natural abundance (4\%), the spectra of the isotopically substituted species were observed in enriched samples. The deuterated ethylene samples were purchased from MSD Isotopes with $\geqslant 98 \%$ enrichment and were used without dilution. $\mathrm{S}^{18} \mathrm{O}_{2}$ (99\% enrichment) was purchased from Alfa Products and was used without dilution to assign the double${ }^{18} \mathrm{O}$ species. The single $-{ }^{18} \mathrm{O}$ species was observed by starting with a mixture of $50 \% \mathrm{~S}^{18} \mathrm{O}_{2}$ and $50 \% \mathrm{~S}^{16} \mathrm{O}_{2}$; the $\mathrm{SO}_{2}$ underwent rapid exchange to form approximately a 2:1:1 mixture of $\mathrm{S}^{16} \mathrm{O}^{18} \mathrm{O}: \mathrm{S}^{18} \mathrm{O}_{2}: \mathrm{S}^{16} \mathrm{O}_{2}$.

\section{Relative intensity tests}

In order to estimate nuclear spin statistical weights for the tunneling doublets, the relative intensities of pairs of transitions were determined by comparison of the signal-tonoise ratios $(\mathrm{S} / \mathrm{N})$ of the two components in the time domain. The $\mathrm{S} / \mathrm{N}$ was estimated as the ratio of the largest peak to peak span in the early portion of the free induction decay (FID) to the largest peak to peak span in the last $10 \%$ of the FID (where only noise is apparent.) Due to the lack of precision in the method by which this value is determined, the $\mathrm{S} / \mathrm{N}$ estimates from many data sets had to be averaged to obtain meaningful numbers for comparison.

The FTMW spectrometer is inherently not well suited for such a measurement of transition intensities. The primary difficulty is that the signal intensity changes greatly depending on the position of the pump and cavity resonant frequencies relative to the transition frequency. To obviate this, relative positions for the pump and the cavity were selected and held constant for each component of the pair of transitions. For one component of the tunneling doublet the FIDs from enough gas pulses (500-5000 depending on the strength of the transition) were averaged to attain a $\mathrm{S} / \mathrm{N}$ of 5 to 20. This was repeated eight to ten times using the same number of pulses to give an average $\mathrm{S} / \mathrm{N}$ estimate for the transition; this usually had a standard deviation of about 10$15 \%$. The pump and the cavity were then positioned the same relative distances from the other component of the doublet and the process was repeated using the same number of shots.

The intensities of the signals are also dependent on both the total backing pressure and the partial pressures of the ethylene and the $\mathrm{SO}_{2}$ in the rare gas. Since the samples are held in 1 or $2 \mathrm{~L}$ glass bulbs, a choice had to be made either to keep the partial pressures constant while allowing the backing pressure to drop, or to keep the backing pressure constant through continued dilutions with rare gas, allowing the partial pressures to change. The former generally gave more consistent results.
Relative intensity measurements were made on the normal, the single- ${ }^{18} \mathrm{O}$, the $1,1-d_{2}$ and the trans-1,2- $d_{2}$ species (see Sec. III E). Overall relative intensities were determined with an estimated accuracy of 10-15\% from four to six pairs of transitions for each isotopic species.

\section{RESULTS AND ANALYSIS}

\section{A. Spectrum of the normal isotopic species}

The $56 a$ and $c$ dipole transitions which were observed are listed in Table I. The transitions occurred as doublets of unequal intensity with the $c$-type transitions split by 25 to 65 $\mathrm{MHz}$ and the $a$-type by a few $\mathrm{kHz}$ to $2 \mathrm{MHz}$. The two components of each doublet exhibited nearly identical Stark effects and this allowed the transitions to be appropriately paired as tunneling doublets and their quantum numbers to be determined.

In the paper detailing initial results on the $\mathrm{C}_{2} \mathrm{H}_{4} \cdot \mathrm{SO}_{2}$ complex ${ }^{5}$ we reported that all the transitions had been simultaneously fit as two interacting states with a change in vibrational quantum number occurring for the $c$-type transitions. Upon subsequent examination, we have reassigned the spectrum (Table I) to two noninteracting states (with no change in vibrational quantum number for the $c$-type transitions) with all the stronger transitions assigned to one state and all the weaker transitions to the other. The assignment results in sum rule differences of less than $10 \mathrm{kHz}$ for all observed transitions connecting common levels. Each state can be fit independently to $A, B, C$ and five quartic distortion constants using the Watson $S$ reduction in a $I^{r}$ representation. ${ }^{14}$ This reassignment improves the fit of the data considerably so that $\Delta v_{\text {rms }}$ for the two states is 5 and $7 \mathrm{kHz}$, compared with $124 \mathrm{kHz}$ in our earlier report. The derived spectroscopic constants are listed in Table II and comparison of the observed and calculated transition frequencies is shown in Table I. The reassignment of the spectrum resulted in only small changes in the rotational constants. The gross geometry reported earlier with the two molecular planes stacked above one another (cf. below and Fig. 1) is therefore still consistent with the observed rotational constants.

Since the two sets of transitions may be independently fit to a standard Watson Hamiltonian, a high barrier onedimensional tunneling motion is suggested. It will be shown below that this motion can be described as an internal rotation of the ethylene about the axis perpendicular to its molecular plane. The complete permutation inversion (PI) group for $\mathrm{C}_{2} \mathrm{H}_{4} \cdot \mathrm{SO}_{2}$ including all feasible permutations of the oxygens, hydrogens and carbons is of order $16\left(G_{16}\right)$. However, if we focus only on the exchange of hydrogens by the internal rotation mentioned above, and the exchange of the two oxygen atoms, the system might be classified by the $\mathrm{G}_{8}$ symmetry group and analyzed by the method employed by Rice $e t$ $a l .{ }^{15}$ for the $\mathrm{CO}_{2} \cdot \mathrm{H}_{2} \mathrm{~S}$ dimer. To draw this analogy, ethylene must be related to $\mathrm{CO}_{2}, \mathrm{H}_{2} \mathrm{~S}$ related to $\mathrm{SO}_{2}$ and the $1 \rightarrow 3$ motion in the $\mathrm{CO}_{2} \cdot \mathrm{H}_{2} \mathrm{~S}$ system corresponds to the internal rotation of the ethylene. This motion together with an additional internal rotation or inversion of the $\mathrm{SO}_{2}$ gives rise to a splitting of a rigid rotor level into four states classified as $A_{1}^{ \pm}, A_{2}^{ \pm}, B_{1}^{ \pm}$, and $B_{2}^{ \pm}$with spin weights of $10,0,6,0$, 
TABLE I. Rotational transitions for $\mathrm{C}_{2} \mathrm{H}_{4} \cdot \mathrm{SO}_{2}$.

\begin{tabular}{|c|c|c|c|c|c|c|}
\hline \multirow[b]{2}{*}{ Transition } & \multicolumn{3}{|c|}{$A_{1}^{\mathrm{a}}$} & \multicolumn{3}{|c|}{$B_{1}{ }^{a}$} \\
\hline & $v_{\mathrm{obs}}{ }^{\mathrm{b}}$ & $o-c^{c}$ & $o-c^{d}$ & $v_{\mathrm{nbs}}{ }^{\mathrm{b}}$ & $o-c^{c}$ & $o-c^{d}$ \\
\hline $1_{10}-0_{00}$ & 8680.110 & -0.004 & -0.102 & 8653.913 & -0.008 & 0.100 \\
\hline $2_{11}-1_{01}$ & 12694.171 & -0.005 & -0.142 & 12668.034 & -0.003 & 0.131 \\
\hline $3_{12}-2_{02}$ & 16890.173 & 0.009 & -0.149 & 16864.198 & 0.000 & 0.185 \\
\hline $22_{21}-2_{11}$ & 13987.687 & 0.005 & -0.275 & 13925.001 & -0.004 & 0.278 \\
\hline $3_{22}-3_{12}$ & 13469.894 & 0.005 & -0.142 & 13407.194 & 0.000 & 0.145 \\
\hline $4_{23}-4_{13}$ & 12788.710 & -0.001 & 0.026 & 12726.062 & 0.000 & -0.033 \\
\hline $5_{24}-5_{14}$ & 11954.065 & -0.004 & 0.232 & 11891.610 & 0.004 & -0.244 \\
\hline $6_{25}-6_{15}$ & 10980.941 & -0.005 & 0.468 & 10918.920 & 0.006 & -0.492 \\
\hline $7_{26}-7_{16}$ & 9891.021 & 0.006 & 0.729 & 9829.805 & -0.007 & -0.781 \\
\hline $2_{20}-2_{12}$ & 15061.264 & 0.002 & -0.354 & 14998.963 & 0.001 & 0.349 \\
\hline $3_{21}-3_{13}$ & 15673.111 & -0.010 & -0.318 & 15611.482 & 0.009 & 0.302 \\
\hline $4_{22}-4_{14}$ & 16581.117 & 0.002 & -0.257 & 16520.810 & -0.009 & 0.246 \\
\hline $4_{04}-3_{12}$ & 8487.551 & 0.000 & -0.084 & 8511.810 & -0.008 & 0.054 \\
\hline $5_{05}-4_{13}$ & 11121.917 & 0.002 & -0.061 & 11144.326 & -0.009 & 0.073 \\
\hline $6_{06}-5_{14}$ & 13382.536 & 0.000 & 0.023 & 13402.311 & 0.006 & 0.043 \\
\hline $7_{07}-6_{15}$ & 15238.525 & -0.002 & 0.007 & & & \\
\hline $2_{02}-1_{01}$ & 7307.476 & -0.002 & -0.098 & 7307.264 & 0.001 & 0.055 \\
\hline $22_{11}-1_{10}$ & 7677.424 & -0.002 & -0.094 & 7677.424 & 0.004 & 0.053 \\
\hline $3_{13}-2_{12}$ & 10449.790 & 0.003 & -0.057 & 10449.466 & 0.001 & 0.022 \\
\hline $3_{03}-2_{02}$ & 10913.461 & -0.002 & -0.122 & 10912.906 & -0.001 & 0.095 \\
\hline $3_{22}-2_{21}$ & 10985.664 & -0.010 & 0.007 & 10985.621 & 0.007 & -0.024 \\
\hline $3_{21}-2_{20}$ & 11061.646 & 0.001 & -0.011 & 11061.982 & 0.006 & -0.028 \\
\hline $3_{12}-2_{11}$ & 11503.463 & -0.004 & -0.120 & 11503.430 & 0.006 & 0.111 \\
\hline $4_{14}-3_{13}$ & 13911.752 & 0.005 & -0.052 & 13911.259 & 0.002 & 0.057 \\
\hline $4_{04}-3_{03}$ & 14464.251 & -0.002 & -0.122 & 14463.109 & 0.000 & 0.151 \\
\hline $4_{23}-3_{22}$ & 14632.196 & -0.006 & 0.000 & 14632.124 & 0.004 & 0.021 \\
\hline $4_{22}-3_{21}$ & 14819.750 & 0.009 & 0.028 & 14820.594 & -0.009 & 0.008 \\
\hline $4_{13}-3_{12}$ & 15313.382 & 0.002 & -0.110 & 15313.254 & 0.002 & 0.197 \\
\hline $5_{05}-4_{04}$ & 17947.743 & -0.002 & -0.092 & & & \\
\hline
\end{tabular}

${ }^{a}$ Symmetry label for rovibrational tunneling state. See the text.

${ }^{\mathrm{b}}$ Observed frequency in $\mathrm{MHz}$.

'Observed-calculated frequency ( $\mathrm{MHz}$ ) using Watson Hamiltonian to fit each state.

${ }^{\mathrm{d}}$ Observed-calculated frequency $(\mathrm{MHz})$ using internal rotation Hamiltonian to fit both states.

respectively. Taking into account the observed intensities of the pairs of doublets, we label the more intense set of transitions in Table I as $A_{1}$, the less intense as $B_{1}$, and suppress the \pm superscripts for simplicity. While this symmetry labeling

TABLE II. Rotational and centrifugal distortion constants of $\mathrm{C}_{2} \mathrm{H}_{4} \cdot \mathrm{SO}_{2}$ (Watson $S$-reduction Hamiltonian)

\begin{tabular}{lcc}
\hline & $A_{1}$ state & $B_{1}$ state \\
\hline$A / \mathrm{MHz}$ & $6673.524(3)^{\mathrm{a}}$ & $6645.981(5)$ \\
$B / \mathrm{MHz}$ & $2007.627(1)$ & $2007.638(1)$ \\
$C / \mathrm{MHz}$ & $1656.105(1)$ & $1656.025(1)$ \\
$D_{J} / \mathrm{kHz}$ & $4.941(19)$ & $4.829(28)$ \\
$D_{J K} / \mathrm{kHz}$ & $168.16(8)$ & $163.55(9)$ \\
$D_{K} / \mathrm{kHz}$ & $504.1(8)$ & $-824.4(10)$ \\
$d_{1} / \mathrm{kHz}$ & $-1.1702(55)$ & $-1.1256(93)$ \\
$d_{2} / \mathrm{kHz}$ & $-0.958(7)$ & $-0.933(11)$ \\
$n^{\mathrm{b}}$ & 29 & 27 \\
$\Delta v_{\mathrm{rms}} / \mathrm{kHz}^{\mathrm{c}}$ & 5 & 7 \\
\hline \hline
\end{tabular}

${ }^{a}$ Uncertainties represent one standard deviation of the fitted parameters. ${ }^{b}$ Number of transitions in the fit.

${ }^{\mathrm{c}} \Delta v=v_{\mathrm{obs}}-v_{\mathrm{calc}}$. of the states is not strictly correct since the set of PI operations associated with the $\mathrm{G}_{8}$ group do not form a complete group for $\mathrm{C}_{2} \mathrm{H}_{4} \cdot \mathrm{SO}_{2}$, this labeling scheme is convenient. No other internal motions of the ethylene have been identified and therefore are ignored; moreover, the matrix elements in Table $\mathrm{V}$ of Rice $e t$ al. ${ }^{15}$ are likely to be valid for $\mathrm{C}_{2} \mathrm{H}_{4} \cdot \mathrm{SO}_{2}$ and permit the qualitative construction of a splitting diagram.

\section{B. Spectra of isotopically substituted species}

To provide insight on the internal motion ( $\mathrm{s}$ ) giving rise to the splitting in the spectrum and to determine the structure of the complex, the nine isotopically substituted species listed in Table III were studied. The spectra of $\mathrm{C}_{2} \mathrm{D}_{4} \cdot \mathrm{SO}_{2}$ (hereafter, $d_{4}$ ), trans-1,2- $\mathrm{C}_{2} \mathrm{H}_{2} \mathrm{D}_{2} \cdot \mathrm{SO}_{2}$ (trans- $\left.d_{2}\right), 1,1-$ $\mathrm{CH}_{2} \mathrm{D}_{2} \cdot \mathrm{SO}_{2} \quad\left(1,1-d_{2}\right), \quad \mathrm{C}_{2} \mathrm{H}_{4} \cdot \mathrm{S}^{18} \mathrm{O}^{16} \mathrm{O}$ (single ${ }^{18} \mathrm{O}$ ), $\mathrm{C}_{2} \mathrm{H}_{4} \cdot \mathrm{S}^{18} \mathrm{O}_{2}$ (double ${ }^{18} \mathrm{O}$ ), and $\mathrm{C}_{2} \mathrm{H}_{4} \cdot{ }^{34} \mathrm{SO}_{2}\left({ }^{34} \mathrm{~S}\right.$ ) were characterized by doublets similar to the normal species. With the exception of the ${ }^{34} \mathrm{~S}$ species, for which too few transitions were measured, the isotopic species were fit as two independent states to the same Hamiltonian used for the normal species; the ${ }^{34} \mathrm{~S}$ species was fit to only $A, B$ and $C$ for each 


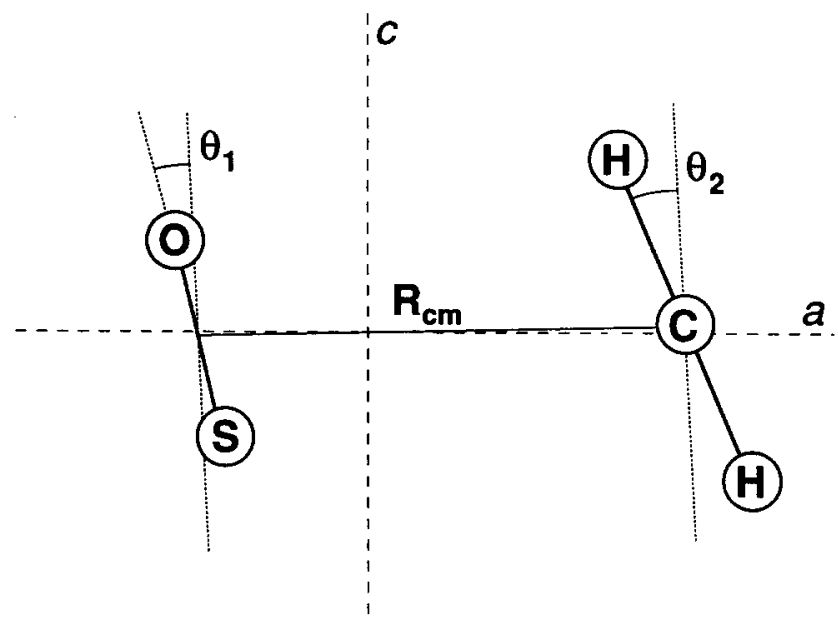

FIG. 1. Projection of the ethylene-SO $\mathrm{SO}_{2}$ complex in the $a-c$ plane showing definitions of $R_{\mathrm{cm}}, \theta_{1}$, and $\theta_{2}$. The line of sight is along the $\mathrm{C}=\mathrm{C}$ bond, with the $O$ atoms eclipsed. $\theta_{1}$ and $\theta_{2}$ are the tilt angles or deviation of the $\mathrm{C}_{2} \mathrm{H}_{4}$ and $\mathrm{SO}_{2}$ planes from being perpendicular to $R_{\mathrm{cm}}$. Angle directions as shown are defined as positive.

state. The spectra of $\mathrm{C}_{2} \mathrm{H}_{3} \mathrm{D} \cdot \mathrm{SO}_{2}\left(d_{1}\right)$ and cis-1,2$\mathrm{C}_{2} \mathrm{H}_{2} \mathrm{D}_{2} \cdot \mathrm{SO}_{2}\left(c i s-d_{2}\right)$ did not exhibit doublets. Intensive searches were made above and below the observed lines in both species for a partner spectrum with no success. Their transitions were fit with the same Watson Hamiltonian. The rotational constants for each species are listed in Table III. The complete set of transitions and spectroscopic constants is available as supplementary material. ${ }^{16}$

Tunneling splittings result when an internal motion in a molecule transforms it to an equivalent structure. The spectra of the $d_{1}$ and $c i s-d_{2}$ species were unsplit apparently because the internal motion did not result in an equivalent form, but rather in a different structural isomer. It has been observed in other systems where two "isotopic" structural isomers can occur that one of the isomers has a significantly higher zero-point energy than the other and is not substantially populated at the low temperature of a supersonic molecular beam. ${ }^{17,18}$ Thus, it seemed likely that the lower energy isomers for the cis-1,2- $d_{2}$ and the $d_{1}$ species had been observed. This was confirmed by switching to $\mathrm{He}$ as a carrier gas to raise the temperature of the beam. Another spectrum for the cis-1,2- $d_{2}$ species was observed which was very much weaker, but which had appropriate rotational constants to be the other structural isomer. (See Structure Section below. The stronger $c i s-d_{2}$ spectrum correlates with the $d$-in isomer in Table III; the weaker spectrum correlates with the $d$-out form.) Due to the weakness of the spectrum only six transitions were measured for the $d$-out form; these were fit to $A, B$ and $C$. A second isomer of the $d_{1}$ species should also be present, however, no search for its spectrum was attempted.

The splitting in the transitions of the isotopically substituted species scaled approximately linearly with deuteration, with the $1_{10}-0_{00}$ transition split by $26 \mathrm{MHz}$ in the normal species, by $13 \mathrm{MHz}$ in the trans- $d_{2}$, by $12 \mathrm{MHz}$ in the $1,1-d_{2}$ species and by $6 \mathrm{MHz}$ in the $d_{4}$ species. The effect of substitution with ${ }^{18} \mathrm{O}$ and ${ }^{34} \mathrm{~S}$ was much less pronounced, with the splitting of the $1_{10}-0_{00}$ transition decreasing to 20 , 22 and $19 \mathrm{MHz}$ for the ${ }^{34} \mathrm{~S}$, the single- ${ }^{18} \mathrm{O}$, and the double${ }^{18} \mathrm{O}$ species, respectively.

\section{Dipole moments}

The dipole moment of the complex was determined from the Stark effect splittings of six transitions. The observed second-order Stark coefficients are shown in Table IV. The values were obtained from plots of $\Delta v \mathrm{vs} E^{2}$. A least squares fit of these data holding $\mu_{b}=0$ yielded a total dipole

TABLE III. Selected molecular constants for $\mathrm{C}_{2} \mathrm{H}_{4} \cdot \mathrm{SO}_{2}$ isotopic species. ${ }^{a}$

\begin{tabular}{|c|c|c|c|c|c|c|}
\hline & $\begin{array}{c}\text { Tunneling } \\
\text { state }\end{array}$ & $\begin{array}{c}A \\
\mathrm{MHz}\end{array}$ & $\begin{array}{c}B \\
\mathrm{MHz}\end{array}$ & $\begin{array}{c}C \\
\mathrm{MHz}\end{array}$ & $n^{\mathrm{b}}$ & $\begin{array}{l}\Delta v_{\mathrm{rms}} \mathrm{c} \\
\mathrm{MHz}\end{array}$ \\
\hline \multirow[t]{2}{*}{$\mathrm{C}_{2} \mathrm{H}_{4} \cdot \mathrm{SO}_{2}$} & $A_{1}$ & $6673.528(4)$ & $2007.627(1)$ & $1656.105(1)$ & 29 & 0.005 \\
\hline & $B_{1}$ & $6645.981(5)$ & $2007.638(1)$ & $1656.025(1)$ & 27 & 0.007 \\
\hline \multirow[t]{2}{*}{$\mathrm{C}_{2} \mathrm{H}_{4} \cdot \mathrm{S}^{18} \mathrm{O}_{2}$} & $A_{1}$ & $6142.062(3)$ & $1967.460(1)$ & $1599.404(1)$ & 21 & 0.003 \\
\hline & $B_{1}$ & $6122.247(5)$ & $1967.473(1)$ & $1599.332(1)$ & 22 & 0.006 \\
\hline \multirow{2}{*}{$\mathrm{C}_{2} \mathrm{H}_{4} \cdot \mathrm{S}^{18} \mathrm{O}^{16} \mathrm{O}$} & $A_{1}$ & $6404.761(4)$ & $1986.685(2)$ & $1627.293(1)$ & 17 & 0.009 \\
\hline & $B_{1}$ & $6381.397(6)$ & $1986.695(2)$ & $1627.213(2)$ & 19 & 0.003 \\
\hline \multirow[t]{2}{*}{$\mathrm{C}_{2} \mathrm{H}_{4} \cdot{ }^{34} \mathrm{SO}_{2}$} & $A_{1}$ & $6643.29(78)$ & $1990.89(33)$ & $1645.47(19)$ & 5 & 0.612 \\
\hline & $B_{1}$ & $6621.41(65)$ & $1990.93(27)$ & $1645.47(15)$ & 5 & 0.509 \\
\hline \multirow[t]{2}{*}{$\mathrm{C}_{2} \mathrm{D}_{4} \cdot \mathrm{SO}_{2}$} & $A_{1}$ & $5959.944(8)$ & $1826.734(2)$ & $1516.985(2)$ & 22 & 0.010 \\
\hline & $B_{1}$ & $5952.735(22)$ & $1826.737(6)$ & $1516.963(4)$ & 22 & 0.027 \\
\hline \multirow[t]{2}{*}{ trans $-\mathrm{C}_{2} \mathrm{H}_{2} \mathrm{D}_{2} \cdot \mathrm{SO}_{2}$} & $A_{1}$ & $6295.474(9)$ & $1911.740(3)$ & $1581.705(2)$ & 21 & 0.011 \\
\hline & $B_{1}$ & $6281.795(9)$ & $1911.902(3)$ & $1581.828(2)$ & 20 & 0.010 \\
\hline \multirow[t]{2}{*}{$1,1-\mathrm{C}_{2} \mathrm{H}_{2} \mathrm{D}_{2} \cdot \mathrm{SO}_{2}$} & $A_{1}$ & $6314.130(28)$ & $1910.580(8)$ & $1583.043(6)$ & 20 & 0.038 \\
\hline & $B_{1}$ & $6300.031(14)$ & $1910.584(4)$ & $1582.993(3)$ & 20 & 0.019 \\
\hline $\mathrm{C}_{2} \mathrm{H}_{3} \mathrm{D} \cdot \mathrm{SO}_{2}(d-i n)^{\mathrm{d}}$ & & $6472.873(6)$ & $1970.948(2)$ & $1626.878(1)$ & 22 & 0.008 \\
\hline$c i s-\mathrm{C}_{2} \mathrm{H}_{2} \mathrm{D}_{2} \cdot \mathrm{SO}_{2}(d-i n)^{d}$ & & $6284.144(30)$ & $1936.738(4)$ & $1599.229(3)$ & 23 & 0.008 \\
\hline$c i s-\mathrm{C}_{2} \mathrm{H}_{2} \mathrm{D}_{2} \cdot \mathrm{SO}_{2}(d-o u t)^{e}$ & & $6300.84(40)$ & $1887.92(11)$ & $1566.08(11)$ & 6 & 0.200 \\
\hline
\end{tabular}

${ }^{a}$ Determined using a Watson centrifugal distortion Hamiltonian ( $S$ reduction).

b Number of transitions in fit.

${ }^{c} \Delta v=v_{\text {obs }}-v_{\text {calc }}$.

d " $d$-in" refers to deuterium substitution closer to the center of mass; i.e., on the $\mathrm{O}$ atom side of $\mathrm{SO}_{2}$ as illustrated in Fig. 1.

e " $d$-out" refers to deuterium substitution more distant from the center of mass; i.e., on the $\mathrm{S}$ atom side as in Fig. 1. 
TABLE IV. Stark coefficients ${ }^{\mathrm{a}}$ for the $A_{1}$ state and dipole moments of ethylene $\cdot \mathrm{SO}_{2}$.

\begin{tabular}{|c|c|c|c|c|c|c|c|}
\hline & \multirow[b]{2}{*}{$|\boldsymbol{M}|$} & \multicolumn{2}{|c|}{$\mathrm{C}_{2} \mathrm{H}_{4} \cdot \mathrm{SO}_{2}$} & \multicolumn{2}{|c|}{ cis $-\mathrm{C}_{2} \mathrm{H}_{2} \mathrm{D}_{2} \cdot \mathrm{SO}_{2}(d-i n)^{\mathrm{b}}$} & \multicolumn{2}{|c|}{$c i s-\mathrm{C}_{2} \mathrm{H}_{2} \mathrm{D}_{2} \cdot \mathrm{SO}_{2}(d-o u t)^{\mathrm{b}}$} \\
\hline & & obs & obs-calc ${ }^{c}$ & obs & obs-calc ${ }^{c}$ & obs & obs-calc ${ }^{c}$ \\
\hline $1_{10}-0_{00}$ & 0 & 3.066 & -0.020 & 3.323 & -0.001 & 3.337 & -0.040 \\
\hline $2_{11}-1_{01}$ & 0 & 0.245 & -0.002 & 0.354 & -0.001 & 0.192 & 0.013 \\
\hline $2_{11}-1_{01}$ & 1 & 3.983 & -0.010 & 4.247 & 0.000 & 4.382 & 0.053 \\
\hline $2_{02}-1_{01}$ & 0 & 1.439 & -0.016 & & & & \\
\hline $202-1_{01}$ & 1 & 3.656 & 0.010 & & & & \\
\hline $3_{03}-2_{02}$ & 0 & -0.676 & 0.002 & -0.620 & -0.004 & -0.884 & -0.150 \\
\hline $3_{03}-2_{02}$ & 2 & 2.526 & 0.029 & 2.640 & 0.001 & 2.592 & -0.082 \\
\hline $4_{04}-3_{03}$ & 2 & & & 0.778 & -0.002 & & \\
\hline \multirow[t]{4}{*}{$3_{13}-2_{12}$} & 1 & & & -0.332 & -0.001 & & \\
\hline & $\mu_{a} / \mathrm{D}$ & \multicolumn{2}{|c|}{$0.629(6)^{d}$} & \multicolumn{2}{|c|}{$0.597(1)$} & \multicolumn{2}{|c|}{$0.678(41)$} \\
\hline & $\mu_{c} / \mathrm{D}$ & \multicolumn{2}{|c|}{$1.525(3)$} & \multicolumn{2}{|c|}{$1.531(1)$} & \multicolumn{2}{|c|}{$1.525(22)$} \\
\hline & $\mu_{T} / \mathrm{D}$ & \multicolumn{2}{|c|}{$1.650(3)$} & \multicolumn{2}{|c|}{$1.643(1)$} & \multicolumn{2}{|c|}{$1.669(26)$} \\
\hline
\end{tabular}

${ }^{a}$ Second-order Stark coefficients $\left(\Delta v / E^{2}\right.$ in units of $\left.10^{5} \mathrm{MHz} /[\mathrm{V} / \mathrm{cm}]^{2}\right)$.

${ }^{\mathrm{b}}$ See footnote Table III.

' Calculated values using the Watson Hamiltonian rotational constants.

${ }^{\mathrm{d}}$ One standard deviation in the fit.

moment, $\mu_{T}=1.650(4) \quad \mathrm{D}$, with components $\mu_{a}=0.629(6) \mathrm{D}$ and $\mu_{c}=1.525(3) \mathrm{D}$. When $\mu_{b}{ }^{2}$ was not fixed to zero, the least-squares fit determined a value for it very nearly equal to zero $\left(\mu_{b}^{2}=-0.04 \mathrm{D}^{2}\right)$.

The dipole moments of the two isomers of the $c i s-d_{2}$ species were also measured. The observed Stark effects and least-squares fits are shown in Table IV. The dipole moment of the higher energy cis-1,2- $d_{2}$ isomer is not as well determined as the other species due to the weakness of the transitions.

\section{Structure}

From planar moments and selection rules, it can be established that the complex has an $a-c$ plane of symmetry. Comparison of the out-of-plane second moment $\left(P_{b b}=0.5\left(I_{a}+I_{c}-I_{b}\right)=\Sigma m_{i} b_{i}{ }^{2}\right)$ of the normal $\left(64.5803 \mathrm{amu} \AA^{2}\right)$ and the ${ }^{34} \mathrm{~S}\left(64.6735 \mathrm{amu} \AA^{2}\right)$ species indicates that the $S$ atom lies in the $a-c$ symmetry plane. Also, $P_{b b}$ of the complex is nearly equal to the sum of $P_{a a}$ of free ethylene and $P_{a a}$ of free $\mathrm{SO}_{2}$ $\left(16.8559+49.0507=65.9066 \mathrm{amu} \AA^{2}\right) .{ }^{19}$ This indicates that $\mathrm{SO}_{2}$ and $\mathrm{C}_{2} \mathrm{H}_{4}$ straddle the symmetry plane as shown in Fig. 1. The two molecular planes are stacked one above the other and their orientation is defined by the parameters $R_{\mathrm{cm}}$, $\theta_{1}$ and $\theta_{2}$ where the tilt angles are defined relative to $R_{\mathrm{cm}}$. In Ref. 3 we reported that $R_{\mathrm{cm}}$ was 3.51 (2) $\AA$ from the normal species data assuming that the $\mathrm{C}_{2} \mathrm{H}_{4}$ and $\mathrm{SO}_{2}$ subunits retain their uncomplexed structures. Values for the angles $\theta_{1}$ and $\theta_{2}$ consistent with the observed rotational constants were also reported, but these were not well determined and their signs were ambiguous.

In a weakly bound complex one would like to determine the structure of each isotopic species separately. The changes in the vibrational amplitudes of low frequency motions in these complexes with isotopic substitution often lead to different average structures for the substituted species, possibly giving some insight on the low frequency motions.
In the case of the $\mathrm{C}_{2} \mathrm{H}_{4} \cdot \mathrm{SO}_{2}$ complex, however, this was not possible. Changes in $R_{\mathrm{cm}}, \theta_{1}$, or $\theta_{2}$ will not affect the $b$ coordinate of any of the atoms; thus the value of $P_{b b}$ is not useful. This leaves three structural parameters to be fit to $P_{a a}$ and $P_{c c} . \quad R_{\mathrm{cm}}$ can be uniquely determined from $\quad I_{b}=P_{a a}+P_{c c}=I_{a}\left(\mathrm{SO}_{2}\right)+I_{a}\left(\mathrm{C}_{2} \mathrm{H}_{4}\right)+R_{\mathrm{cm}}^{2}$ $\times \mu\left(\mathrm{C}_{2} \mathrm{H}_{4} \cdot \mathrm{SO}_{2}\right)$, but only a range of correlated values for $\theta_{1}$ and $\theta_{2}$ can be determined which are consistent with the observed moments of inertia for an individual isotopic series.

A least-squares fit to the $A_{1}$ state moments of inertia of all the isotopic species can resolve some of the ambiguity and results in the two sets of structural parameters in Table $V$, labeled I and II. The magnitude and direction of the tilt angle $\theta_{1}$ of the sulfur dioxide are determined to be $\sim 8-9^{\circ}$ from the ${ }^{34} \mathrm{~S}$ and ${ }^{18} \mathrm{O}$ data. Using the data from the deuterated ethylenes to determine the angle $\theta_{2}$ is not so straightforward and fits of similar quality ( $\Delta I_{\mathrm{rms}}$ ) are obtained for values of $+20.4^{\circ}$ and $-20.6^{\circ}$. The isotopic species that are sensitive to $\theta_{2}$ are the $d_{1}$ and both cis- $d_{2}$ species. For example, the tilt angle and deuterium positions for both fits place

TABLE V. Structures for $\mathrm{C}_{2} \mathrm{H}_{4} \cdot \mathrm{SO}_{2}$ from least-square fits of the moments of inertia of all the isotopic species using constants from the Watson Hamiltonian for the $A_{1}$ state (columns I and II) and from the internal rotation Hamiltonian (column III)."

\begin{tabular}{lccc}
\hline & I & II & III $^{\mathrm{b}}$ \\
\hline$\theta_{1} / \mathrm{deg}$ & $8.4(2.6)^{\mathrm{c}}$ & $8.7(2.6)$ & $12.1(2.1)$ \\
$\theta_{2} / \mathrm{deg}$ & $20.4(1.3)$ & $-20.6(1.3)$ & $20.9(1.4)$ \\
$R_{\mathrm{cm}} / \AA$ & $3.505(1)$ & $3.505(1)$ & $3.504(1)$ \\
$\Delta I_{r m s} \mathrm{~d} / \mathrm{amu} \mathrm{\AA} \AA^{2}$ & 0.41 & 0.41 & 0.44 \\
\hline \hline
\end{tabular}

"The ethylene and $\mathrm{SO}_{2}$ structures were not varied (Ref. 19) except for the S-O distance which was relaxed to $1.417 \AA$ A to match $P_{b b}$.

${ }^{\text {b }}$ Structure preferred by authors.

' Positive angles indicate counter-clockwise rotation, negative angles clockwise. See Fig. 1. The values in parenthesis are the statistical uncertainties associated with the fit.

${ }^{\mathrm{d}} \Delta I_{\mathrm{rms}}$ where $\Delta I=I_{\mathrm{obs}}-I_{\text {calc }}$. 
TABLE VI. Predicted (pred) and observed (obs) rotational constants and dipole components for the two isomers of $c i s-1,2-\mathrm{C}_{2} \mathrm{H}_{2} \mathrm{D}_{2} \cdot \mathrm{SO}_{2}$.

\begin{tabular}{|c|c|c|c|c|c|c|}
\hline & \multicolumn{3}{|c|}{$d-i n^{\mathrm{a}}$} & \multicolumn{3}{|c|}{$d$-out $t^{a}$} \\
\hline & \multicolumn{2}{|c|}{$\begin{array}{c}\text { Pred }^{\mathrm{b}} \\
\theta_{2}\end{array}$} & \multirow[t]{2}{*}{ Obs } & \multicolumn{2}{|c|}{$\begin{array}{c}\text { Pred }^{b} \\
\theta_{2}\end{array}$} & \multirow[t]{2}{*}{ Obs } \\
\hline & $+20.4^{\circ}$ & $-20.6^{\circ}$ & & $+20.4^{\circ}$ & $-20.6^{\circ}$ & \\
\hline$A / \mathrm{MHz}$ & 6294 & 6300 & 6284 & 6309 & 6302 & 6300 \\
\hline$B / \mathrm{MHz}$ & 1934 & 1934 & 1937 & 1889 & 1888 & 1887 \\
\hline$C / \mathrm{MHz}$ & 1597 & 1596 & 1599 & 1565 & 1565 & 1566 \\
\hline$\mu_{a} / \mathrm{D}$ & 0.60 & 0.65 & 0.597 & 0.66 & 0.60 & 0.678 \\
\hline$\mu_{c} / \mathrm{D}$ & 1.53 & 1.50 & 1.530 & 1.51 & 1.54 & 1.526 \\
\hline
\end{tabular}

"The $d$-in refers to the cis- $d_{2}$ isomer with the ethylene tilted to bring the $\mathrm{d}$ atoms closer to the center of mass; $d$-out implies a tilt placing the $d$ atoms farther from the center of mass (see Fig. 1).

${ }^{b}$ Rotational constants predicted with the structural parameters from the least squares fit in Table V, columns I and II.

the $D$ atoms closer to the center of mass for the $d_{1}-i n$ and cis$d_{2}$-in species. However, the deuterium substitution may lie on either the sulfur side $\left(\theta_{2}=20.4^{\circ}\right)$ or the oxygen side $\left(-20.6^{\circ}\right)$ of the $\mathrm{SO}_{2}$. Conversely, the cis- $d_{2}$-out species places the deuterium farther from the center of mass with the same ambiguity as to the side. The $a$-principal axis is nearly colinear with the $R_{\mathrm{cm}}$ vector and the two possible orientations give fits of similar quality based on $\Delta I_{\text {rms }}$ (Table V).

Analysis using Kraitchman's equations also does not help to resolve the ambiguity since the $|a|$ and $|c|$ coordinates for the inner and outer $\mathbf{H}$-atoms for either tilt angle are within $0.1 \AA$ of each other. However, closer inspection of the rotational constants predicted by the two structures obtained from the least-squares fits suggests that the plus $(+)$ tilt angle is more consistent with the isotope shifts observed for the two $c i s-d_{2}$ species. This is summarized in Table VI where the rotational constants calculated for the two values of $\theta_{2}$ are compared with the experimental results. As can be seen in Table VI, there is a significant difference between the $A$ constants for the $d$-in and $d$-out species which differ by 2 $\mathrm{MHz}$ for $\theta_{2}$ negative and $15 \mathrm{MHz}$ for $\theta_{2}$ positive; however, as the absolute agreement with experiment for the $A$ constants is comparable to this difference, this is not a definitive test.

A more compelling indication of a positive value of $\theta_{2}$ comes from the dipole moments of the two $c i s-d_{2}$ species. This rationale makes use of the small changes in the dipole moment components caused by principal axes rotation upon isotopic substitution. As the sign of the dipole moment cannot be determined, there are four choices for the orientation of the dipole moment of the complex. The most reasonable choice places the dipole moment nearly parallel to the symmetry axis of the $\mathrm{SO}_{2}$, as the dipole moment of the complex is likely to be dominated by the permanent dipole moment of the $\mathrm{SO}_{2}, 1.63305 \mathrm{D}^{20}$ This requires an induced moment of $0.298 \mathrm{D}$, which is consistent with an $a b$ initio calculation (see below), while the other three orientations require induced moments of $0.925 \mathrm{D}$ or larger. The two cis $-\mathrm{d}_{2}$ species provide the largest axis rotations upon substitution and thus the most sensitive test of the structure. If $\theta_{2}$ were positive, the rotation would decrease the $\mu_{a}$ component and increase the $\mu_{c}$ for $d$-in and vice versa for $d$-out (Table VI). Conversely, the opposite should be seen if $\theta_{2}$ were negative. The changes are easily large enough to be observed and significantly larger than what would be expected due to the permanent dipole moment of cis-1,2- $\mathrm{C}_{2} \mathrm{H}_{2} \mathrm{D}_{2}{ }^{21}$ The observed dipole moment components for these two species are consistent with the positive value of $\theta_{2}$ and inconsistent with the negative one.

The overall least-squares fit residual of $0.41 \mathrm{amu} \AA^{2}$, as well as the poor agreement in the $A$ constants for the $c i s-d_{2}$ isomers, can be attributed to averaging effects of large amplitude vibrational motions. This is most apparent when comparing $P_{b b}$ for the normal species with that calculated from the free subunits (see above). The large amplitude motions in the complex give a structure in which the average $b$ coordinates of the atoms are smaller than they would be in a rigid structure, thus reducing $P_{b b}$; the other inertial parameters will be similarly contaminated. An attempt to further improve the structural analysis will be dealt with in the next section where corrections to the moments due to the internal motion will be discussed. This is structure III which is also listed in Table V for completeness.

Finally, it is interesting to note that the dipole moment determined for the $\mathrm{C}_{2} \mathrm{H}_{4} \cdot \mathrm{SO}_{2}$ complex $(1.650 \mathrm{D})$ is very similar to the dipole moment of the free $\mathrm{SO}_{2}$ subunit ( 1.633 D). However, the dipole moment of the complex is rotated some $10^{\circ}$ away from the $\mathrm{C}_{2}$ axis of $\mathrm{SO}_{2}$. A projection of the dipole moment of $\mathrm{SO}_{2}$ for $\theta_{1}=12^{\circ}$ predicts dipole components of $\mu_{a}=0.340 \mathrm{D}$ and $\mu_{c}=1.597 \mathrm{D}$, while the measured values are $\mu_{a}=0.629 \mathrm{D}$ and $\mu_{c}=1.525 \mathrm{D}$. This can be explained as arising from an induced dipole moment of magnitude $0.298 \mathrm{D}$ with components of $\mu_{a}=0.289 \mathrm{D}$ and $\mu_{c}=-0.072 \mathrm{D}$. Following analogous calculations in $\mathrm{PF}_{3}-$ rare gas complexes, ${ }^{22}$ GAUSSIAN $86^{23}$ was used to calculate the electric field around $\mathrm{SO}_{2}\left(6-31 \mathrm{G}^{*}\right.$ basis set $)$. A simple model treating ethylene as a point polarizability located at its center of mass with components $\alpha_{a a}=5.53 \AA^{3}, \alpha_{b b}=3.65$ $\AA^{3}$ and $\alpha_{c c}=3.58 \AA^{324(a)}$ (in the principal axis system of the ethylene) predicts an induced moment of $0.406 \mathrm{D}$, with components $\mu_{a}=0.384 \mathrm{D}$ and $\mu_{c}=-0.131 \mathrm{D}$. The same approach was used to estimate the field that ethylene exerts on $\mathrm{SO}_{2}$ (with polarizability components of $\alpha_{a a}=5.32 \AA^{3}$, $\alpha_{b b}=3.51 \AA^{3}$, and $\left.\alpha_{c c}=3.01 \AA^{3}\right)^{24(b)}$ which resulted in induced dipole components from $\mathrm{SO}_{2}$ of $0.137 \mathrm{D}$ and $\mu_{c}=-0.048 \mathrm{D}$. This procedure overestimates the total induced dipole components by about a factor of 2 although their signs agree with the experimentally derived values; it suggests that the majority of the induced moment upon complexation arises from the ethylene.

\section{E. Internal motion, nuclear spin statistics and barrier to internal rotation}

Apart from a few exceptions where the splitting is too small to be observed, the transitions of $\mathrm{C}_{2} \mathrm{H}_{4} \cdot \mathrm{SO}_{2}$ occur as doublets of unequal intensity. A number of internal motions can be envisioned which could account for this: internal rotation of the $\mathrm{SO}_{2}$ about its symmetry axis, "over-the-top" inversion of the $\mathrm{SO}_{2}$ taking the complex through a $C_{2 v}$ tran- 
sition state or rotation of the ethylene about one of its symmetry axes. Since the strong and weak components can be fit independently with a Watson Hamiltonian, the barrier to the internal motion must be relatively high. This also eliminates the inversion motion of the $\mathrm{SO}_{2}$ as this motion would change the direction of the $\mu_{c}$-dipole component of the complex. The possibility of the $\mathrm{SO}_{2}$ subunit tunneling about its local $\mathrm{C}_{2}$ axis can also be eliminated on the grounds that two tunneling states are observed. This motion would involve the exchange of two ${ }^{16} \mathrm{O}$ nuclei $(I=0)$ and, as in the case of $\mathrm{Ar} \cdot \mathrm{SO}_{2},{ }^{25}$ half the rotation-tunneling levels would be symmetry forbidden.

Three possible motions remain viz. the rotation of the ethylene about each of its $C_{2}$ axes. To distinguish among these, the splittings in the spectra of the three doubly deuterated isotopic species were considered. For a spectrum to exhibit tunneling splitting in its transitions, the tunneling motion must result in an equivalent species with identical rotational constants. (In rare cases, such as in the $\mathrm{H}^{35} \mathrm{Cl} \cdot \mathrm{H}^{37} \mathrm{Cl}$ dimer, ${ }^{26}$ tunneling effects between nonequivalent species are also observed, but there is no evidence of this in the present system.) The unsplit spectra of the $c i s-d_{2}$ and $d_{1}$ species, therefore, eliminated a rotation of ethylene about its $b$ axis as this motion would give equivalent species with identical rotational constants.

In selecting between the two remaining possibilities, the nuclear spin statistics associated with the tunneling doublets in the trans- $d_{2}$ and $1,1-d_{2}$ species were considered. Levels with different nuclear spin statistical weights occur only in cases where equivalent nuclei are exchanged by the motion and the Pauli principle requires that the symmetry of the
TABLE VII. Relative intensity of the tunneling doublets in ethylene $\cdot \mathrm{SO}_{2}{ }^{\mathrm{a}}$

\begin{tabular}{lccc}
\hline \hline & $A_{1}$ & $:$ & $B_{1}$ \\
\hline $\mathrm{C}_{2} \mathrm{H}_{4} \cdot \mathrm{SO}_{2}$ & 1.55 & $:$ & 1.00 \\
$\mathrm{C}_{2} \mathrm{H}_{4} \cdot \mathrm{S}^{18} \mathrm{O}^{16} \mathrm{O}$ & 1.68 & $:$ & 1.00 \\
trans $-\mathrm{C}_{2} \mathrm{H}_{2} \mathrm{D}_{2} \cdot \mathrm{SO}_{2}$ & 1.00 & $:$ & 1.34 \\
$1,1-\mathrm{C}_{2} \mathrm{H}_{2} \mathrm{D}_{2} \cdot \mathrm{SO}_{2}$ & 1.00 & $:$ & 1.02 \\
\hline
\end{tabular}

The ratios have an uncertainty of $\pm 15 \%$.

nuclear spin states be properly paired with the symmetry of a given rotation-tunneling level. The expected statistical weights for the exchange of two protons and two deuterons are 5:7 $\left(A_{1}: B_{1}\right)$. The results of the relative intensity measurements are given in Table VII (see also experimental); the trans- $d_{2}$ species exhibits these spin statistics, whereas the $1,1-d_{2}$ species does not. This indicates that the motion must be one in which equivalent nuclei are exchanged in the trans$d_{2}$ species but where protons are exchanged for deuterons in the 1,1- $d_{2}$. The motion consistent with this is the rotation of the ethylene in its molecular plane, i.e., about its $c$ axis. To ensure that the measured spin statistical weights were not simply fortuitous, the relative intensities of the two states in the normal species and the single $-{ }^{18} \mathrm{O}$ species were also examined. For the exchange of two pairs of protons, statistical weights of 10:6 $\left(A_{1}: B_{1}\right)$ would be expected, and again the measured values (Table VII) are in reasonable agreement.

Further evidence for the effect of the tunneling motion on spin statistics can be seen in the deuterium nuclear quadrupole coupling patterns in the trans- $d_{2}$ and the 1,1- $d_{2}$ species, as shown in Fig. 2 . In the case of the 1,1- $d_{2}$ species, each
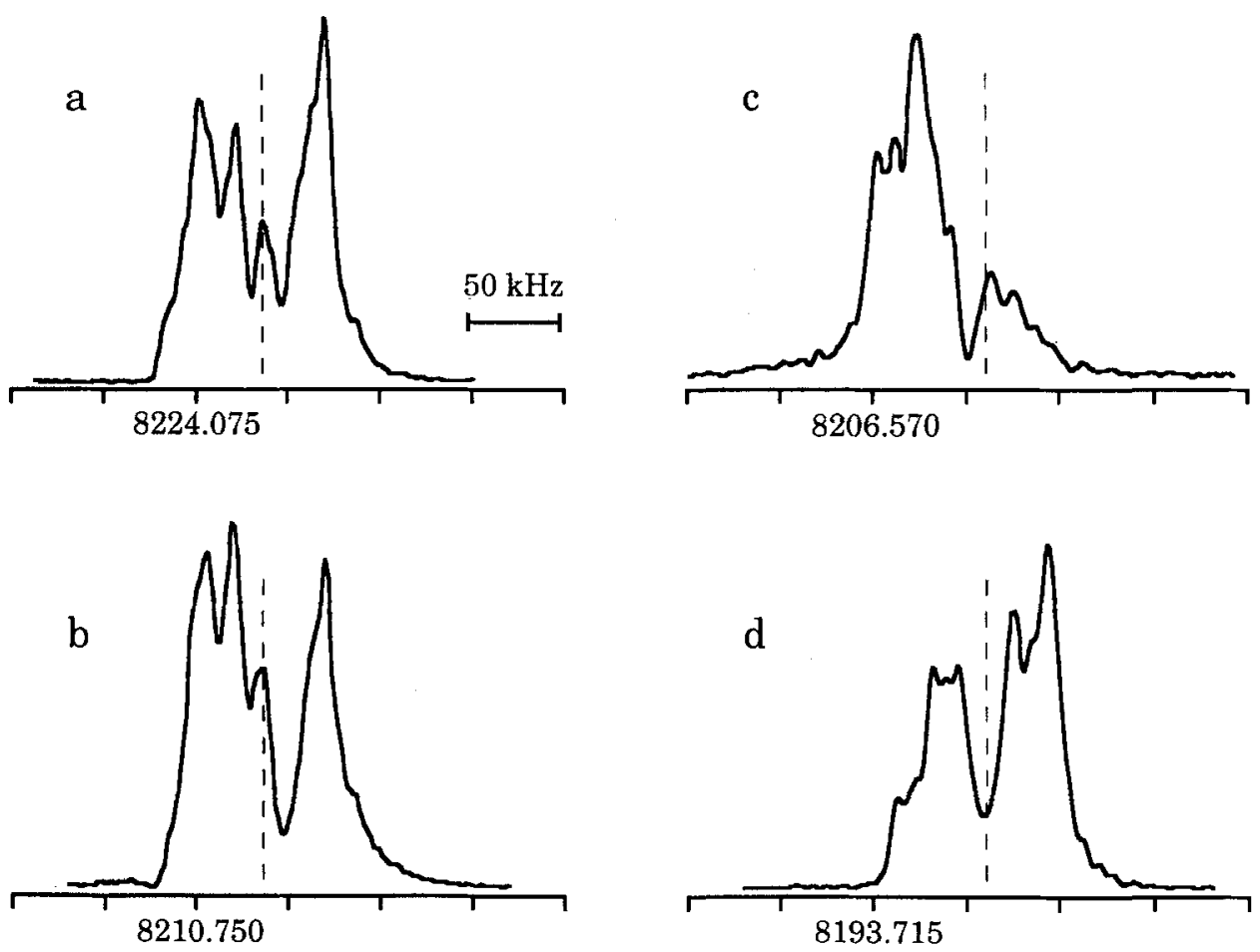

FIG. 2. Power spectra of the $1_{10}-0_{00}$ transition showing nuclear quadrupole coupling hyperfine patterns in both tunneling states for the $1,1-\mathrm{C}_{2} \mathrm{H}_{2} \mathrm{D}_{2} \cdot \mathrm{SO}_{2}$ and trans $-\mathrm{C}_{2} \mathrm{H}_{2} \mathrm{D}_{2} \cdot \mathrm{SO}_{2}$ species. Sampling conditions were chosen to minimize Doppler splitting $(\leqslant 30 \mathrm{kHz})$. The dashed lines indicate center frequencies estimated using the $\chi$ 's from the $\mathrm{C}_{2} \mathrm{H}_{3} \mathrm{D} \cdot \mathrm{SO}_{2}$ species in Table XI. (a) $1,1-d_{2}, A_{1}$ state; (b) $1,1-d_{2}, B_{1}$ state; (c) trans- $d_{2}, A_{1}$ state; (d) $t$ trans- $d_{2}, B_{1}$ state. 
component of the doublet $(a, b)$ exhibits identical nuclear quadrupole coupling patterns, whereas in the trans- $d_{2}$ species $(c, d)$, the pattern for each component is distinctly different. As with the relative intensities, this difference arises because identical nuclei are exchanged upon internal rotation in the trans- $d_{2}$ species while in the $1,1-d_{2}$ species nonequivalent pairs of $\mathbf{H}$ and $D$ atoms would be exchanged. Thus, in the trans- $d_{2}$ species only the hyperfine transitions allowed by the Pauli principle appear in each state. In the $1,1-d_{2}$, there is no exchange of identical nuclei and therefore all nuclear spin states are allowed for each rotation-tunneling level.

The splittings in the spectrum thus result from an internal rotation of the ethylene in its molecular plane. Given this and the geometry of the complex, the spectrum may be fit using the following internal rotation Hamiltonian ${ }^{27}$ :

$$
\begin{aligned}
\mathbf{H}= & A \mathbf{J}_{a}^{2}+B \mathbf{J}_{b}^{2}+C \mathbf{J}_{c}^{2}+D_{a c}\left(\mathbf{J}_{a} \mathbf{J}_{c}+\mathbf{J}_{c} \mathbf{J}_{a}\right) \\
& -2\left(Q_{a} \mathbf{J}_{a}+Q_{c} \mathbf{J}_{c}\right) \mathbf{j}+F^{2} \mathbf{j}+\frac{1}{2} V_{2}(1-\cos 2 \alpha),
\end{aligned}
$$

where

$$
\begin{aligned}
& A=\frac{\hbar^{2}}{2 I_{a a}}+F \rho_{a}^{2}, \quad B=\frac{\hbar^{2}}{2 I_{b b}}, \quad C=\frac{\hbar^{2}}{2 I_{c c}}+F \rho_{c}^{2}, \\
& D_{a c}=F \rho_{a} \rho_{c}, \quad Q_{a}=F \rho_{a}, \quad Q_{c}=F \rho_{c}, \\
& F=\frac{\hbar^{2}}{2 r I_{\alpha}}, \quad r=1-\lambda_{a} \rho_{a}-\lambda_{c} \rho_{c}, \\
& \rho_{a}=\frac{\lambda_{a} I_{\alpha}}{I_{a a}}, \quad \rho_{c}=\frac{\lambda_{c} I_{\alpha}}{I_{c c}} .
\end{aligned}
$$

$\mathbf{J}_{a}, \mathbf{J}_{b}$, and $\mathbf{J}_{c}$ are the projections of the total angular momentum onto the principal axes, $a, b$, and $c$, respectively; $\mathbf{j}$ is the angular momentum of the internal rotor, $\alpha$ is the internal rotation coordinate, and $V_{2}$ is the twofold barrier height; $I_{a a}$, $I_{b b}$ and $I_{c c}$ are the principal moments of inertia of the rigid rotor; $I_{\alpha}$ is the moment of inertia of the internal rotor; $\lambda_{a}\left(\lambda_{c}\right)$ is the direction cosine between the internal rotor axis
( $c$ axis of the ethylene subunit), and the $a(c)$ inertial axis. The Hamiltonian matrix of $\mathbf{H}$ is constructed using $|J K M\rangle \cdot\left[(2 \pi)^{-1 / 2}\right] e^{i m \alpha}$, where $|J K M\rangle$ are symmetric rotor wave functions and $\left[(2 \pi)^{-1 / 2}\right] e^{i m \alpha}$ are free rotor wave functions. The resulting infinite matrix, which factors into $A_{1}$ and $B_{1}$ blocks, is diagonalized with the free-rotor basis set truncated at $m= \pm 13$. The sum of the squares of the direction cosines should be equal to one $\left(\left[\lambda_{a}\right]^{2}+\left[\lambda_{c}\right]^{2}=1\right)$, however, due to the large-amplitude vibrations in van der Waals complexes, this constraint is not necessarily maintained and was relaxed. For the case of $\mathrm{C}_{2} \mathrm{H}_{4} \cdot \mathrm{SO}_{2}$, the best fit is obtained at $\lambda_{a}^{2}+\lambda_{c}^{2}=1.016$. The moment of inertia of the internal rotor $I_{\alpha}$ is set equal to $I_{c c}$ of free ethylene. To account for centrifugal distortion effects, the Watson $S$-reduction quartic centrifugal distortion Hamiltonian is added to the internal rotation Hamiltonian of Eq. (1). This Hamiltonian was applied to the isotopic species with an $a-c$ plane of symmetry since the equilibrium direction cosine $\lambda_{b}$ between the internal rotor axis and the $b$ inertial axis is zero. For $1,1-\mathrm{C}_{2} \mathrm{H}_{4} \cdot \mathrm{SO}_{2}$ and $\mathrm{C}_{2} \mathrm{H}_{4} \cdot \mathrm{S}^{18} \mathrm{O}^{16} \mathrm{O}, \lambda_{b}$ is different from zero (no plane of symmetry), however contributions from this effect were neglected and the same Hamiltonian was employed.

The constants obtained from this fit for the normal species are given in Table VIII and agreement with experimental frequencies is shown in Table $I$. The frequency fits and the barriers calculated for the isotopes exhibiting internal rotation splittings are summarized in Table IX. The agreement is quite good, with all barriers about $31 \mathrm{~cm}^{-1}$, although the quality of the frequency fits is typically an order of magnitude poorer compared to the Watson Hamiltonian. This deterioration is probably associated, at least in part, with the neglect in the internal rotation Hamiltonian of the fact that the rotational constants should vary with internal rotation angle $(\alpha)$. In this regard, the orientation of the $\mathrm{C}_{2} \mathrm{H}_{4}$ relative to the $a$ principal axis makes $A$ less sensitive to $\alpha$ than $B$ and $C$. However, inspection of the $B$ and $C$ constants obtained

TABLE VIII. Molecular constants for $\mathrm{C}_{2} \mathrm{H}_{4} \cdot \mathrm{SO}_{2}$ derived with the internal rotation Hamiltonian [see Eq. (1) ].

\begin{tabular}{lclr}
\hline \hline \multicolumn{2}{c}{ Fitted parameters } & \multicolumn{2}{c}{ Fixed parameters } \\
\hline$A / \mathrm{MHz}$ & $8741.25(23)$ & $F / \mathrm{MHz}$ & 32747.868 \\
$B / \mathrm{MHz}$ & $2009.697(20)$ & $Q_{c} / \mathrm{MHz}$ & 601.245 \\
$C / \mathrm{MHz}$ & $1664.542(12)$ & $Q_{a} / \mathrm{MHz}$ & 8255.867 \\
& & $D_{a c} / \mathrm{MHz}$ & 151.576 \\
$D_{J} / \mathrm{kHz}$ & $3.98(39)$ & $A^{\prime b} / \mathrm{MHz}$ & 6659.912 \\
$D_{J K} / \mathrm{kHz}$ & $162.9(33)$ & $B^{\prime} / \mathrm{MHz}$ & 2009.697 \\
$D_{K} / \mathrm{kHz}$ & $-159.3(300)$ & $C^{\prime} / \mathrm{MHz}$ & 1653.504 \\
$d_{1} / \mathrm{kHz}$ & $-1.26(21)$ & & \\
$d_{2} / \mathrm{kHz}$ & $-1.64(19)$ & $\theta_{a}{ }^{a}$ & $20^{\circ}$ \\
& & $\theta_{c}$ & $74^{\circ}$ \\
$V_{2} / \mathrm{cm}{ }^{-1}$ & $30.159(13)$ & & \\
$n^{\mathrm{e}}$ & 56 & & \\
$\Delta v_{\mathrm{rms}} / \mathrm{kHz}$ & 244 & & \\
\hline \hline
\end{tabular}

\footnotetext{
$\lambda_{a}=\cos \theta_{a}$.

${ }^{\mathrm{b}} A^{\prime}=\breve{h}^{2} / 2 I_{a a}=A-F \rho_{a}{ }^{2}$, etc.

' See footnotes, Table II.
} 
TABLE IX. Calculated $V_{2}$ barriers to internal rotation for isotopic species of ethylene $\cdot \mathrm{SO}_{2}$.

\begin{tabular}{llll}
\hline \hline & Barrier/cm & $n^{\mathrm{a}}$ & $\Delta v_{\mathrm{rms}}{ }^{\mathrm{a}}$ \\
\hline $\mathrm{C}_{2} \mathrm{H}_{4} \cdot \mathrm{SO}_{2}$ & $30.16(2)^{\mathrm{b}}$ & 56 & 0.244 \\
$\mathrm{C}_{2} \mathrm{H}_{4} \cdot \mathrm{S}^{18} \mathrm{O}_{2}$ & $30.39(2)$ & 43 & 0.154 \\
$\mathrm{C}_{2} \mathrm{D}_{4} \cdot \mathrm{SO}_{2}$ & $31.59(2)$ & 44 & 0.039 \\
trans $-\mathrm{C}_{2} \mathrm{H}_{2} \mathrm{D}_{2}-\mathrm{SO}_{2}$ & $30.97(2)$ & 41 & 0.068 \\
$1,1-\mathrm{C}_{2} \mathrm{H}_{2} \mathrm{D}_{2} \cdot \mathrm{SO}_{2}$ & $30.84(2)$ & 40 & 0.086 \\
$\mathrm{C}_{2} \mathrm{H}_{4} \cdot \mathrm{S}^{18} \mathrm{O}^{16} \mathrm{O}$ & $30.32(2)$ & 26 & 0.103 \\
\hline \hline
\end{tabular}

a See footnotes, Table II.

${ }^{\mathrm{b}}$ Uncertainty in parentheses is $2 \sigma$.

from the Watson Hamiltonian fits (Table II) show small variations between the $A_{1}$ and $B_{1}$ states and this probably correlates with the success of Eq. (1) in fitting the spectrum. An effort was made to estimate the effects of parametrizing the rotational constants as a function of $\alpha$ on the splittings and the barrier. Application of Quade's treatment ${ }^{28}$ indicated that the $\alpha$ dependence of the rotational constants for the two tunneling states is identical in first order. The effects from $\alpha$ must arise in second or third order, but these calculations were formidable and were not undertaken except to note that the expansion parameter $R \approx I_{\alpha} I_{a a} /$ $I_{b b} I_{c c}=0.020$, implying a rapid convergence in the corrections. In a different vein, the perturbation formulation of Herschbach ${ }^{29}$ was employed to estimate the second order corrections to the rotational constants assuming a barrier of $30 \mathrm{~cm}^{-1}$. This gave differences between the constants for the $A_{1}$ and $B_{1}$ states of $\Delta A=12.5 \mathrm{MHz}, \Delta B=0.0 \mathrm{MHz}$ and $\Delta C=0.07 \mathrm{MHz}$ for the normal species. The changes in $B$ and $C$ correlate well with the observed differences and suggest that the neglect of the $\alpha$ dependence on the rotational constants in all probability does not seriously affect the barrier estimate. Moreover, given the dependence of the effective rotational constants on the direction cosines of the internal rotation axis with respect to the principal inertial axes, and noting that the $A$ constant is the most sensitive to the direction cosine term, it is clear that the internal rotation axis is close to the $a$ principal axis, confirming a tunneling motion of ethylene in its molecular plane. Attempts to fit the transitions to the other possible motions of the ethylene using the Hamiltonian in Eq. (1) resulted in $\Delta v_{\text {rms }}$ (obs-calc) values of several $\mathrm{MHz}$.

Finally, the structure derived from least-squares fitting of the "internal rotation-corrected" moments of inertia is quite similar to that determined solely from the $A_{1}$ constants and is listed in Table $\mathrm{V}$ as structure III. The differences from structure I can be used to estimate limits for the uncertainties of the structural parameters. We prefer structure III over I since the internal rotation effects have been partially minimized. The structural parameters are still contaminated by vibrational averaging effects and should be considered analogous to those of an $r_{0}$ structure. $^{30}$

\section{F. Deuterium nuclear quadrupole coupling}

For the $\mathrm{C}_{2} \mathrm{H}_{3} \mathrm{D} \cdot \mathrm{SO}_{2}$ species, the deuterium nuclear quadrupole hyperfine structure was resolved and assigned. The assigned hyperfine components are listed in Table X, along with the calculated nuclear quadrupole coupling constants. The coupling constants were determined by a leastsquares fitting procedure which treats the quadrupole interactions as perturbations on the rotational energies. ${ }^{31}$

To interpret the nuclear quadrupole coupling constants, the electric field gradients at the deuterium site arising from unperturbed (i.e., uncomplexed) ethylene and $\mathrm{SO}_{2}$ were calculated using GAUSSIAN $86 .{ }^{23}$ The calculations were initially done at the Hartree-Fock level using a $6-31 \mathrm{G}^{*}$ basis set. To test the reliability of the electric field gradients, the calculations were repeated with STO-3G and 4-31G basis sets and the three calculations agreed to within $10 \%$. The $6-31 \mathrm{G}^{*} a b$ initio electric field gradients were rotated into the principal inertial axis system of the complex to estimate the contributions from each subunit to the nuclear quadrupole coupling constants. These are shown in Table XI. The calculations indicate that the quadrupole coupling in the complex is due almost entirely to the electric field gradient arising from the

TABLE X. Deuterium nuclear quadrupole hyperfine structure and coupling constants for $\mathrm{C}_{2} \mathrm{H} \mathrm{H}_{3} \mathrm{D} \cdot \mathrm{SO}_{2}$.

\begin{tabular}{|c|c|c|c|c|c|c|c|c|c|}
\hline$J^{\prime}$ & $K_{p}^{\prime}$ & $K_{o}^{\prime}$ & $F^{\prime}$ & $J^{\prime \prime}$ & $K_{p}^{\prime \prime}$ & $K_{o}^{\prime \prime}$ & $F^{\prime \prime}$ & $\begin{array}{c}v_{\mathrm{obs}} \\
(\mathrm{MHz})\end{array}$ & $\begin{array}{r}\text { obs-calc } \\
(\mathrm{MHz})\end{array}$ \\
\hline 1 & 1 & 0 & 1 & 0 & 0 & 0 & 1 & 8443.448 & 0.0005 \\
\hline 1 & 1 & 0 & 2 & 0 & 0 & $\mathbf{0}$ & 1 & 8443.412 & -0.0028 \\
\hline 1 & 1 & 0 & 0 & 0 & 0 & 0 & 1 & 8443.368 & 0.0023 \\
\hline 3 & 2 & 2 & 2 & 2 & 2 & 1 & 1 & 10787.829 & -0.0006 \\
\hline 3 & 2 & 2 & 4 & 2 & 2 & 1 & 3 & 10787.809 & 0.0007 \\
\hline 3 & 2 & 2 & 3 & 2 & 2 & 1 & 2 & 10787.770 & 0.0000 \\
\hline 3 & 2 & 2 & 3 & 3 & 1 & 2 & 3 & 12998.799 & 0.0003 \\
\hline 3 & 2 & 2 & 4 & 3 & 1 & 2 & 4 & 12998.786 & 0.0010 \\
\hline 3 & 2 & 2 & 2 & 3 & 1 & 2 & 2 & 12998.779 & -0.0013 \\
\hline 2 & 2 & 1 & 3 & 2 & 1 & 1 & 3 & 13505.709 & 0.0010 \\
\hline 2 & 2 & 1 & 1 & 2 & 1 & 1 & 1 & 13505.684 & -0.0010 \\
\hline 4 & 0 & 4 & 5 & 3 & 1 & 2 & 4 & 8415.703 & 0.0030 \\
\hline 4 & 0 & 4 & 4 & 3 & 1 & 2 & 3 & 8415.665 & -0.0030 \\
\hline 4 & 2 & 3 & 5 & 3 & 2 & 2 & 4 & 14368.568 & -0.0013 \\
\hline 4 & 2 & 3 & 4 & 3 & 2 & 2 & 3 & 14368.554 & 0.0013 \\
\hline \multicolumn{4}{|c|}{$\chi_{a a}=-0.119(1) \mathrm{MHz}$} & \multicolumn{4}{|c|}{$\chi_{b b}=0.010(1) \mathrm{MHz}$} & \multicolumn{2}{|c|}{$\chi_{c c}=0.109(1) \mathrm{MHz}$} \\
\hline
\end{tabular}


TABLE XI. Nuclear quadrupole coupling constants of $\mathrm{C}_{2} \mathrm{H}_{3} \mathrm{D} \cdot \mathrm{SO}_{2}$.

\begin{tabular}{crrr}
\hline \hline & & \multicolumn{2}{c}{ Calculated $(\mathrm{MHz})^{\mathrm{a}}$} \\
\cline { 3 - 4 } & & \multicolumn{1}{c}{$\mathrm{C}_{2} \mathrm{H}_{4}$} & \multicolumn{1}{c}{$\mathrm{SO}_{2}$} \\
\hline$\chi_{a a}$ & -0.119 & -0.1029 & 0.0005 \\
$\chi_{b b}$ & 0.010 & 0.0182 & 0.0000 \\
$\chi_{c c}$ & 0.109 & 0.0847 & -0.0005 \\
\hline \hline
\end{tabular}

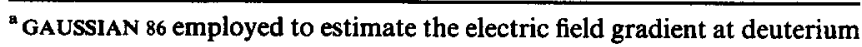
arising from free ethylene and free $\mathrm{SO}_{2}$ at the position of the deuterium (see the text).

ethylene charge distribution. There does not appear to be any previous measurement of the coupling constants for free $\mathrm{C}_{2} \mathrm{H}_{3} \mathrm{D}$ and the accuracy of our calculated values is difficult to estimate, precluding any firm conclusion regarding the effects of complex formation of the coupling constants except that they are small.

\section{G. Electrostatic modeling of the complex}

Orientational preferences in van der Waals complexes are often determined by electrostatic components of the interaction..$^{7-9}$ To investigate whether such an argument can be used to interpret the structure of the $\mathrm{C}_{2} \mathrm{H}_{4} \cdot \mathrm{SO}_{2}$ complex, a distributed multipole analysis as proposed by Buckingham and Fowler was explored. ${ }^{7}$ In this model, all polarization, dispersion, and charge transfer effects are ignored. Point multipoles are placed on atoms and bond centers to approximate the electronic charge distribution in the molecule. The repulsive term is modeled by hard spheres of van der Waals radii $^{32}$ placed on the atoms.

The values calculated by Buckingham and Fowler for the distributed multipoles of ethylene and $\mathrm{SO}_{2}$ were used directly. ${ }^{7}$ For the experimental-like stacked structures, the energies were calculated using the experimental $R_{\mathrm{cm}}$ distance; for the others the distances were set by the contact of hard spheres. Table XII shows calculated electrostatic interaction energies for four different configurations. Of these, the experimental configuration (I) has the largest stabilization energy. For structure I, a shallow electrostatic minimum is obtained as $\theta_{1}$ is varied (Fig. 3) at about $\theta_{1}=10^{\circ}-15^{\circ}$, consistent with the experimental structure. As $\theta_{2}$ is varied, with $\theta_{1}$ fixed at the experimental value, a minimum is obtained at $+20^{\circ}\left(875 \mathrm{~cm}^{-1}\right)$. Considering the difficulty in determining the sign of $\theta_{2}$ experimentally, it is interesting to note that a substantially lesser interaction $\left(549 \mathrm{~cm}^{-1}\right)$ is obtained for $\theta_{2}=-20^{\circ}$.

It is also interesting to compare the electrostatic interaction energy with the binding energy estimated from the pseudo-diatomic model. The model of Millen, ${ }^{33}$ which assumes that the $D_{J}$ distortion constant arises only from the van der Waals stretching mode, gives $k=16 \pi^{4} \mu_{\mathrm{D}}^{2} R_{\mathrm{cm}}^{2} D_{J}^{-1} h^{-1}$ $\times\left[4 B^{4}+4 C^{4}-(B+C)^{2}(B-C)^{2}\right]$. From this, a force constant of $0.057 \mathrm{mdyn} / \AA \AA$ is obtained and, assuming a Lennard-Jones 6-12 potential, a binding energy of $490 \mathrm{~cm}^{-1}$ is calculated. This is considerably smaller than the electrostatic interaction energy of $875 \mathrm{~cm}^{-1}$. (Of course, there is no intrinsic reason for these two estimates to agree; for example,
TABLE XII. Electrostatic energies $\left(\mathrm{cm}^{-1}\right)$ for different structures of $\mathrm{C}_{2} \mathrm{H}_{4} \cdot \mathrm{SO}_{2}$ from distributed multipole analysis.

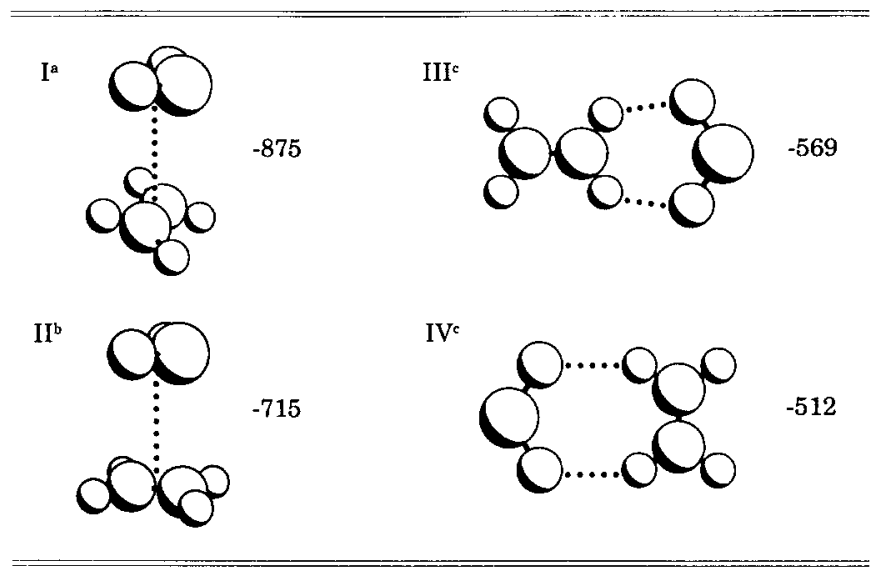

${ }^{a}$ Stacked $\mathrm{C}_{2} \mathrm{H}_{4}$ and $\mathrm{SO}_{2}$; experimental $\theta_{1}$ and $\theta_{2}$.

${ }^{b}$ Stacked parallel planes.

${ }^{\circ} \mathrm{C}_{2} \mathrm{H}_{4}$ and $\mathrm{SO}_{2}$ coplanar.

the electrostatic model does not include a quantitative repulsive term.) These estimates can be compared with experimental values of $\Delta H$ for $\mathrm{SO}_{2}$ complexes of $1088(30) \mathrm{cm}^{-1}$ for trans-2-butene in the gas phase ${ }^{1(\mathrm{a})}$ and $350-1250 \mathrm{~cm}^{-1}$ for a variety of alkene and aromatic species in hexane solvent. $^{1(b)}$ This scatter in experimental, calculated and extrapolated values makes an estimate of the true binding energy of $\mathrm{C}_{2} \mathrm{H}_{4} \cdot \mathrm{SO}_{2}$ unclear except that it is probably in the range of $500-1000 \mathrm{~cm}^{-1}$. The difference between structures I and II in Table XII gives an estimate of about $160 \mathrm{~cm}^{-1}$ for the internal rotation barrier, considerably different from the values of $31 \mathrm{~cm}^{-1}$ from the spectra.

Electrostatic interactions as modeled by the Buckingham-Fowler paradigm are certainly not sufficient to completely rationalize the binding, structure and internal dynamics of this complex. The measured dipole moment components indicate that polarization effects are also important. Nevertheless, the comparisons made above indicate

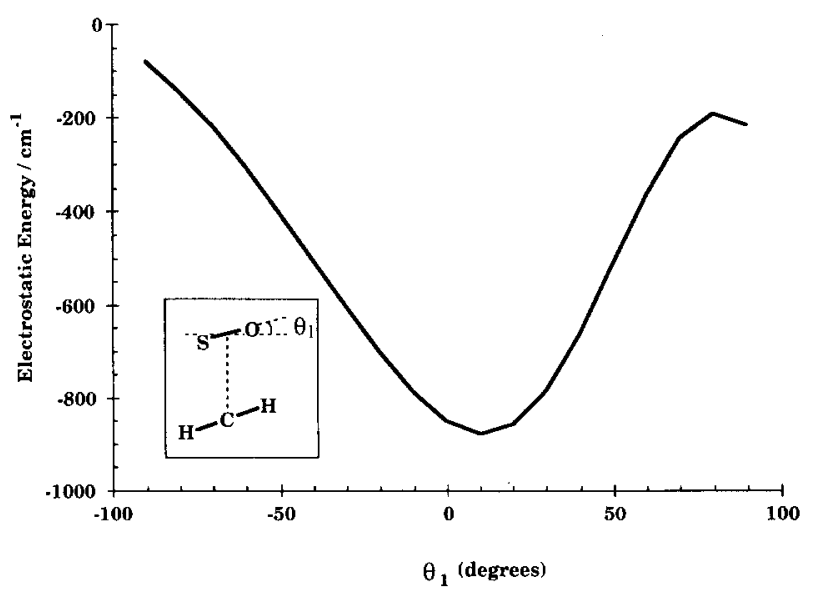

FIG. 3. Electrostatic stabilization energy calculated using the distributed multipole model vs $\theta_{1}$, tilt angle of the $\mathrm{SO}_{2}$. The tilt angle of ethylene, $\theta_{2}$ is fixed at $+20^{\circ}$, the experimental value. 
that electrostatic interactions play a significant role in determining the structure of this complex.

We also note that a small number of unassigned transitions have been observed. However, we believe that they arise from either another conformer or higher molecular weight aggregates of $\mathrm{C}_{2} \mathrm{H}_{4}$ and $\mathrm{SO}_{2}$. Attempts to assign these transitions have been unsuccessful but we believe that their assignment is unlikely to affect the conclusions of this study.

\section{ACKNOWLEDGMENTS}

This research was supported by Grants No. CHE8614340 and CHE8917945 from the National Science Foundation. A. Andrews was the recipient of a University of Michigan Regents Graduate Fellowship (1987-90). We acknowledge very helpful discussions with Dr. C. Gillies and several members of the Molecular Spectroscopy Division at NIST in Gaithersburg, Maryland.

'(a) I. Hanazaki, J. Phys. Chem. 76, 1982 (1972); (b) D. Booth, F. S. Dainton, and K. J. Ivin, Trans. Faraday Soc. 55, 1293 (1959).

${ }^{2}$ (a) L. J. Andrews and R. M. Keefer, J. Am. Chem. Soc. 73, 4169 (1951);

(b) L. J. Andrews, Chem. Rev. 54, 713 (1954).

${ }^{3}$ (a) L. Fredin, Chem. Scr. 4, 97 (1973); (b) L. Nord, J. Mol. Struct. 96, 27 (1982).

${ }^{4}$ (a) J. S. Muenter, R. L. DeLeon, and A. Yokozeki, Faraday Discuss. Chem. Soc. 73, 63 (1982); (b) R. L. DeLeon and J. S. Muenter, Atmos. Environ. 18, 995 (1984).

${ }^{5}$ M. S. LaBarge, K. W. Hillig II, and R. L. Kuczkowski, Angew. Chem. Int. Engl. Ed. 27, 1356 (1988).

'J. Z. Gillies, C. W. Gillies, R. D. Suenram, F. J. Lovas, and W. Stahl, J. Am. Chem. Soc. 111, 3073 (1989).

${ }^{7}$ A. D. Buckingham and P. W. Fowler, Can. J. Chem. 63, 2018 (1985).

${ }^{8}$ P. A. Kollman, Acc. Chem. Res. 10, 365 (1977).

${ }^{9}$ K. Morokuma, Acc. Chem. Res. 10, 294 (1977).

${ }^{10}$ T. J. Balle and W. H. Flygare, Rev. Sci. Instrum. 52, 33 (1981).

"K. W. Hillig II, J. Matos, A. Scioly, and R. L. Kuczkowski, Chem. Phys. Lett. 133, 359 (1987).

${ }^{12}$ R. K. Bohn, K. W. Hillig II, and R. L. Kuczkowski, J. Phys. Chem. 93, 3456 (1989).
${ }^{13}$ K. Tanaka, H. Ito, K. Harada, and T. Tanaka, J. Phys. Chem. 80, 5893 (1984).

14J. K. G. Watson, J. Chem. Phys. 46, 1935 (1967)

${ }^{15}$ J. K. Rice, L. H. Coudert, K. Matsumura, R. D. Suenram, F. J. Lovas, W. Stahl, D. J. Pauley, and S. G. Kukolich, J. Chem. Phys. 92, 6408 (1990).

${ }^{16}$ See AIP Document no. PAPS JCPSA-93-7030-12 for 12 pages of tables of $\mathrm{C}_{2} \mathrm{H}_{4} \cdot \mathrm{SO}_{2}$. Order by PAPS number and journal reference from American Institute of Physics, Physics Auxiliary Publication Service, 335 E. 45th Street, New York, NY 10017.

${ }^{17}$ T. R. Dyke, B. J. Howard, and W. Klemperer, J. Chem Phys. 56, 2442 (1972).

${ }^{18}$ H. S. Gutowsky, C. Chuang, J. D. Keen, T. D. Klots, and T. Emilsson, J. Chem. Phys. 83, 2070 (1985).

${ }^{19}$ M. D. Harmony, V. W. Laurie, R. L. Kuczkowski, R. H. Schwendeman, D. A. Ramsay, F. J. Lovas, W. J. Lafferty, and A. G. Maki, J. Chem. Phys. Ref. Data 8, 619 (1979).

${ }^{20}$ F. J. Lovas, J. Chem. Phys. Ref. Data 14, 395 (1985).

${ }^{21}$ Apparently, the dipole moment of $c i s-\mathrm{C}_{2} \mathrm{H}_{2} \mathrm{D}_{2}$ has not been determined. The value for $1,1-C_{2} H_{2} D_{2}$ is 0.0091 D. E. Hirota, Y. Endo, S. Saito, $K$. Yoshida, I. Yamaguchi, and K. Mochida, J. Mol. Spectrosc. 89, 223 (1981).

${ }^{22}$ A. Taleb-Bendiab, M. S. LaBarge, L. L. Lohr, R. C. Taylor, K. W. Hillig II, R. L. Kuczkowski, and R. K. Bohn, J. Chem. Phys. 90, 6949 (1989).

${ }^{23}$ J. M. Frisch, J. S. Binkley, H. B. Schlegel, K. Raghavachari, C. F. Melius, R. L. Martin, J. J. P. Stewart, F. W. Bobrowicz, C. M. Rohlfing, L. R. Kahn, D. J. DeFrees, R. Seeger, R. A. Whiteside, D. J. Fox, E. M. Fluder, and J. A. Pople, Gaussian 86 (Carnegie-Mellon Quantum Chemistry Publishing Unit, Pittsburgh, PA, 1986).

${ }^{24}$ (a) Y. Chen and T. Oka, J. Chem. Phys. 88, 5282 (1988); (b) W. F. Murphy, J. Raman Spectrosc. 11, 339 (1981).

${ }^{25}$ R. L. DeLeon, A. Yokozeki, and J. S. Muenter, J. Chem. Phys. 73, 2044 (1980).

${ }^{26}$ N. Ohashi and A. S. Pine, J. Chem. Phys. 81, 73 (1984).

${ }^{27}$ J. D. Swalen and D. R. Herschbach, J. Chem. Phys. 27, 100 (1957).

${ }^{28}$ (a) C. R. Quade and C. C. Lin, J. Chem. Phys. 38, 540 (1963); (b) C. R. Quade, J. Chem. Phys. 47, 1073 (1967).

${ }^{29}$ D. R. Herschbach, J. Chem. Phys. 31, 91 (1959).

${ }^{30}$ R. H. Schwendeman, Critical Evaluation of Chemical and Physical Structural Information; edited by D. R. Lide and M. A. Paul (National Academy of Sciences, Washington, D. C., 1974), pp. 74-115.

${ }^{31}$ W. Gordy and R. L. Cook, Molecular Microwave Spectra (Wiley, New York, 1984), pp. 413-418.

${ }^{32} \mathrm{~L}$. Pauling, The Nature of the Chemical Bond (Cornell University, Ithaca, NY, 1960), p. 260.

${ }^{33}$ D. J. Millen, Can. J. Chem. 63, 1477 (1985). 